\title{
Mudanças paradigmáticas e educação ambiental: Concepções socioambientais da contemporaneidade
}

As crises socioambientais da modernidade, sejam de caráter social, ambiental ou econômicos, agravadas pelo modelo capitalista de produção e consumo dominantes, instigam as sociedades pela busca de caminhos que aumentem o equilíbrio das relações entre o homem e a natureza e diminuam as iniquidades sociais. Nesta perspectiva, destaca-se que tais processos dependem de mudanças paradigmáticas que reflitam valores éticos abrangentes e que tem na educação ambiental uma forte aliada, ao incentivar a reflexão critica e a participação dos sujeitos diante das políticas públicas. Conforme análise de literatura pertinente à temática, a legislação brasileira vem dando apoio formal à educação ambiental, mesmo que na prática ela não seja prioridade. Desta feita, é possível afirma que o momento é de importantes mudanças paradigmáticas no que se refere à relevância atribuída à educação ambiental, no entanto, a efetivação prática de ações ainda esta aquém das reais necessidades das sociedades contemporâneas.

Palavras-chave: Educação Ambiental; Mudanças Paradigmáticas; Meio Ambiente.

\section{Paradigmatic changes and environmental education: Socio- environmental conceptions of contemporaneity}

\begin{abstract}
Social and environmental crises of modernity, whether environmental or economic character, aggravated by the capitalist model of production and dominant consumption, instigate societies by looking for ways to increase the balance of relations between man and nature and reduce social inequities. In this perspective, it is emphasized that these processes depend on paradigmatic changes that reflect comprehensive ethical values and environmental education has a strong ally, to encourage critical reflection and participation of individuals in the face of public policies. As appropriate to the theme of literature analysis, Brazilian legislation has been giving formal support to environmental education, even though in practice it is not a priority. This time, it is possible claims that the timing is important paradigmatic changes with regard to the importance given to environmental education, however, the practice effective actions is still short of actual needs of contemporary societies.
\end{abstract}

Keywords: Environmental Education; Paradigmatic Changes; Environment.

\section{Topic: Educação Ambiental}

Reviewed anonymously in the process of blind peer

Luis Claudio dos Santos Bastos Júnior

Universidade Federal de Sergipe

http://lattes.cnpq.br/9426245633389734

E-mail

Roseli Pereira Nunes

Universidade Federal de Sergipe

http://lattes.cnpq.br/038179477621907

E-mail
Received: 19/01/2016

Approved: 14/11/2015
Referencing this:

BASTOS JUNIOR, L. C. S.; NUNES, R. P.. Mudanças paradigmáticas e educação ambiental: Concepções socioambientais da contemporaneidade. Revista Ibero-Americana de Ciências Ambientais, v.7, n.1, p.106-114, 2016. DOI: http://doi.org/10.6008/SPC2179-6858.2016.001.0009 


\section{INTRODUÇÃO}

O entendimento da interação 'moderna' do ser humano com o ambiente tem representado um estimulo para a realização de estudos em relação às mudanças paradigmáticas e às abordagens e práticas da educação ambiental no contexto da contemporaneidade, uma vez que estes estudos e investigações vêm ampliando o foco para além de levantamentos restritos aos conceitos acerca do meio ambiente e/ou fenômenos e problemas naturais. Assim, faz-se necessário depreender que a interação existente entre o homem e o entorno perpassa pelos aspectos sociais, culturais e econômicos das sociedades.

A relação do homem com o restante da natureza físico-natural já foi integrada de tal forma que não havia a percepção da existência do meio ambiente como algo extra-humano. No entanto, esta relação alterou-se de maneira significativa ao longo do tempo, de forma que a natureza começou a ser vista como uma entidade à parte. Para compreendê-la, tornou-se necessário um intermediário, função muitas vezes atribuída às religiões. Depois de várias outras concepções, a natureza chegou ao período da Revolução Industrial como exclusiva fornecedora de matérias-primas, dentro de um processo no qual os recursos naturais poderiam ser livremente dominados pelo homem (CARVALHO, 1995).

Para Reigota (1994), a maneira como as pessoas percebem o seu entorno é parte de um fenômeno histórico que de certa forma é resultado de uma série de fatores relacionados à cultura, ao modo de vida e aos tipos de relações que são estabelecidas com os espaços e recursos, dentre outros. Condições estas que inferem na existência de diferentes olhares para o mesmo local e que estão em constante transformação diante das mudanças sociais.

Nesta perspectiva, costuma-se fazer uso da educação ambiental como prática por meio da qual os conceitos e princípios acerca da natureza, do meio ambiente e do homem como sendo parte atuante desta interação, são disseminados entre os grupos. Uma postura holística proporciona a solução mais adequada para tratar das questões ambientais e da relação do homem neste contexto, por acreditar que "[...] o modelo cartesiano é reducionista, fragmentado sem vida e mecânico" (GRUN, 2002, p.63).

Como consequência, a educação ambiental adquire um caráter interdisciplinar e integrador, reforçando a utilização de uma abordagem complexa para a compreensão da problemática socioambiental, como resultado das interações entre o sistema natural e social. Pois, "[...] a proposta da educação ambiental consiste em reconhecer que uma análise ambiental não pode ser realizada pelas ilhas dos sistemas de conhecimento. Somente um estudo interdisciplinar pode compreender a complexidade ambiental" (SANTOS \& SATO, 2006, p.45). Desta feita, os autores enfatizam a necessidade de inovar na ética dos sujeitos para um novo olhar das técnicas, da produção econômica e das relações sociais.

Assim, a educação ambiental diz respeito a uma mudança de paradigma que implica tanto uma revolução científica quanto política. Na concepção de Kuhn (1992), revoluções paradigmáticas, sejam científicas, políticas ou educacionais, entre outras, são episódios de desenvolvimento não cumulativo nos quais um paradigma antigo é substituído por um novo. Desta feita, a educação ambiental, ao ter como 
preceito fundamental 'educar para a cidadania', pode construir a possibilidade da ação política, no sentido de contribuir para formar uma coletividade que é responsável pelo local que habita e por seu entorno.

Nesse sentido, podemos ressaltar que as políticas de educação ambiental desenvolvidas no Brasil são postas a atuarem enquanto aliadas dos processos que promovem uma espécie de 'sociologia das emergências', como estratégia metodológica para superar o paradigma da racionalidade instrumental ate então atuante no país e em grande parte do mundo, silenciando os opostos à participação, à diversidade e à solidariedade, assim como em busca da emancipação.

\section{DISCURSÃO TEÓRICA}

\section{Mudanças Paradigmáticas: Evolução Científica em Abordagens Socioambientais}

A humanidade tem passado por inúmeras e variadas revoluções no conhecimento que impulsionam a superação de antigos limites. Cada uma dessas fases é descrita como uma mudança paradigmática, expressão introduzida pelo físico, historiador e filósofo inglês Thomas Kuhn (1992, p.13) ao considerar paradigmas "as realizações científicas universalmente reconhecidas que, durante algum tempo, fornecem problemas e soluções modulares para uma comunidade de praticantes de uma ciência".

A evolução histórica mostra que os paradigmas científicos vão se modificando constantemente. Segundo Assmann (1998), não há paradigma permanente, uma vez que eles são historicamente mutáveis, relativos e naturalmente seletivos. A evolução da humanidade é continua e dinâmica, assim modificam-se os valores, as crenças, os conceitos e as ideias acerca da realidade. Essas mudanças paradigmáticas estão diretamente relacionadas ao olhar e à vivência do observador.

Diante do supracitado, é possível afirmar que os paradigmas são necessários, pois fornecem um referencial que possibilita a organização da sociedade, em especial da comunidade científica quando propõe continuamente novos modelos para entender a realidade. Podendo, por outro lado, limitar a visão de mundo quando há resistência ao processo de mudança e insistência em se manter o paradigma conservador. Neste contexto, a aceitação ou resistência a um paradigma reflete diretamente na abordagem teórica e prática da atuação dos profissionais em todas às áreas de conhecimento.

As ideias de Kuhn são bastante utilizadas não apenas porque nos ajudam a entender como emerge uma nova perspectiva, mas também como e por que tais opiniões novas sempre se opõem certa resistência, durante algum tempo. Vale destacar que um paradigma é um esquema para a compreensão e a explicação de certos aspectos da realidade. Ainda que Kuhn tenha se referido majoritariamente à ciência, a expressão foi amplamente adotada, pois, abordam-se paradigmas educacionais, paradigmas políticos, mudanças de paradigmas na medicina, etc.

É neste contexto de mudança paradigmática que as temáticas socioambientais são entendidas na atualidade, haja vista emergirem de fenômenos que já não podem ser estudados tão somente por um enfoque científico tradicional, uma vez que resultam de outras variáveis como o contexto social do indivíduo, 
da atividade perceptiva das pessoas em relação às condições ambientais criadas por e para elas. Assim, de diversas realidades, o que requer dos estudiosos uma posição que possa fundir a objetividade do cientista e a preocupação do humanista.

No entanto, Veiga (2007) ressalta que as temáticas ambientais continuam sendo, na maioria das vezes, tratadas de forma atomizada onde costuma ser destacado somente o enfoque ambientalista que as direciona apenas aos aspectos de fauna e flora, preservação e conservação, desconsiderando o homem e as relações sociais como estando fora deste contexto. De maneira semelhante, o termo socioambiental costuma ser superficialmente trabalhado e, quando mencionado, é reduzido à mera mudança semântica sem a real abrangência de significado pertinente ao vocábulo.

Para a compreensão desta forma de abordagem solidificada em bases complexas, as abordagens e as práticas em educação ambiental, sejam estas formais, informais ou não formais, necessitam priorizar um viés inovador que vise conferir relevância ao fato de que a interação existente entre o homem e o entorno perpassa pelos aspectos sociais, culturais e econômicos das sociedades, ou seja, as relações socioambientais são, antes de tudo, relações sociais.

Na visão de Capra (1982) trata-se de propor uma visão holística como novo paradigma para trabalhar as temáticas socioambientais, considerando-se não apenas o conjunto das múltiplas dimensões das realidades do sujeito, mas também dos diversos aspectos da pessoa humana sob a forma da complexidade, de suas representações e formas de ser no mundo.

Mediante tal perspectiva, torna-se imprescindível a utilização de análises que visem fundir conhecimentos de variados campos da ciência com ações que levem os sujeitos envolvidos a atuarem não somente enquanto receptores de determinadas comandas, mas sim, que os tornem protagonistas ativos da realidade percebida em seu entorno. Desta feita, tem-se atribuído à educação ambiental a função de principal viés para a articulação entre os diferentes saberes dos sujeitos - escolares e sociais, por exemplo assim como, instrumento para a formação do pensamento crítico acerca não somente da relação do homem enquanto ser à parte da natureza, mas sim, de sua interação harmônica com o entorno tendo em vista o contexto socioambiental.

\section{Concepções Contemporâneas da Educação Ambiental}

A denominação - educação ambiental - foi oficializada a partir da Carta de Belgrado, documento elaborado por especialistas em educação e áreas afins das ciências relacionadas com a ecologia, difundido pela UNESCO, a partir de 1975. Nela, encontramos os fundamentos básicos de uma proposta pedagógica, que se convencionou chamar de educação ambiental, e que se relaciona à conscientização, capacidade de avaliação e participação dos educandos (REIGOTA, 1999).

De acordo com Felizola (2007), a Carta de Belgrado preconizou a necessidade de uma nova ética global, capaz de promover a erradicação da pobreza, da fome, do analfabetismo, da poluição, da exploração e da dominação humana. A proposta apoiava as iniciativas com caráter de preservação e conservação dos 
recursos naturais, usando como suporte o ensino da Biologia, Ecologia e Geografia, fase em que a educação ambiental se baseava fundamentalmente na assimilação de informações.

A respeito desta contextualização, Pedrini (1997) assevera que na ocasião, acrescentou-se aos princípios básicos da educação ambiental, a importância que deveria ser direcionada às relações naturezasociedade, que posteriormente, na década de 80 , daria origem à vertente socioambiental da educação ambiental, cuja máxima é o entendimento das relações do homem não somente com a natureza, mas com o entorno como um todo.

Em uma perspectiva mais contemporânea, Dias (2004) afirma que a educação ambiental nasce como um processo educativo que tem como objetivo conduzir os envolvidos a um saber ambiental materializado nos valores éticos e nas regras políticas de convívio social e de mercado, vislumbrando a importância da harmonia entre o homem e a natureza, assim como os benefícios e prejuízos da apropriação e do uso dela. Nesta perspectiva, ela deve, portanto, ser direcionada para a cidadania ativa, considerando o sentido de pertencimento e co-responsabilidade que, por meio da ação coletiva e organizada, busca a compreensão e a superação das causas estruturais e conjunturais dos problemas ambientais.

Em outras palavras, o referido autor diz que a educação ambiental é um desmembramento do processo de educação chamado 'convencional', que visa construir uma cultura ecológica capaz de compreender a natureza e a sociedade como dimensões intrinsecamente relacionadas e que não podem mais ser pensadas separadamente, seja nas decisões governamentais, seja nas ações da sociedade civil.

Considera-se que as sociedades contemporâneas vislumbram que a educação ambiental possibilite que o ser humano se perceba como um dos elementos da natureza, assim como da sociedade que a transforma, tendo a capacidade de criar o próprio ambiente, mantendo os ambientes de outras espécies. Neste sentido, Costa (1999) acrescenta a concepção de uma percepção nítida acerca da interdependência entre o desenvolvimento econômico e a existência, disponibilidade e limites dos suportes naturais.

Torna-se imprescindível elucidar que a educação ambiental é baseada na sensibilização das pessoas quanto ao fato de que elas estão integradas ao ambiente, a um sistema vivo e a uma comunidade, e que suas ações nos interferem. Para tais contextos, destaca-se que na educação ambiental o que se percebe como fundamental é aquilo que venha a estimular as crianças, os jovens e os adultos a dar-se conta de que podem contribuir para melhorar a vida de sua comunidade e influenciar concretamente no mundo em que vivem, realizando atividades úteis por si próprios e participando ativamente de procedimentos que possibilitem a reflexão e a ação.

Destaca-se então a importância da transformação de valores e atitudes em prol das ações socioambientais, mediante processos educativos de caráter formal, informal ou não formal, que prolonguem o ensino-aprendizagem para além dos muros escolares, onde Freire $(1997$, p.91) coloca que "[...] o aluno conhece e vive não é somente aquela empiricamente apreendida; é também, a realidade sonhada, a das ideias, das crenças, das emoções, das aspirações, das fantasias, dos desejos".

Tal condição permite depreender a necessidade de ações que visem a execução de procedimentos que agucem e estimulem a conscientização ambiental dos sujeitos pertencentes às diversas realidades, 
corroborando com a importância de mobiliza-los para a formação de uma ética socioambiental numa perspectiva de que os envolvidos possam absorver a ideia de 'interação consciente' com a natureza, afim de que haja uma mudança de atitude.

Na perspectiva de Reigota (2001), a educação ambiental tem como uma das suas finalidades a efetivação das políticas públicas de proteção ao meio ambiente, mas este processo além de políticas públicas deve ser uma perspectiva de conscientização da sociedade a qual tem ou teria uma grande parcela de responsabilidade neste processo de degradação ambiental. É neste sentido que se pensa em uma proposta de educação ambiental interdisciplinar disseminando cada vez mais uma prática educativa de respeito mutuo ao meio ambiente.

No que se refere à educação formal e à legislação brasileira, a questão ambiental foi integrada nos Parâmetros Curriculares Nacionais como tema transversal a ser trabalhado visando priorizar o desenvolvimento de valores, atitudes e posturas éticas, capazes de possibilitar aos alunos, a formulação de conhecimento critico em defesa do ambiente e construção de uma sociedade autossustentável considerando aspectos naturais, sociais e econômicos.

\section{A Educação Ambiental e as Políticas Públicas Nacionais}

O termo políticas públicas não possui uma única definição. Ao contrário, possui variadas possibilidades que privilegiam aspectos diversificados como ações e não ações, processo decisório, atores políticos, planejamento. Dentre estas definições, Vianna Junior citado por Vallejo (2003, p.16) entende política pública como “[...] uma ação planejada do governo que visa, por meio de diversos processos, atingir alguma finalidade. Esta definição, agregando diferentes ações governamentais introduz a ideia de planejamento, de ações coordenadas".

O meio ambiente é elencado com uma preocupação real do governo brasileiro, principalmente após a Conferência de Estocolmo, em 1972, quando a temática passou a ser inserida na agenda de compromisso das Nações participantes. Por conseguinte, foi criada a Secretaria Especial de Meio ambiente, órgão diretamente ligado à presidência da república. No entanto, a educação ambiental só começou a fazer parte do planejamento sustentável do país a partir de 1977 após a I Conferência Intergovernamental de Educação Ambiental de Tibilise.

Outro passo foi dado em 1981, com a Política Nacional de Meio Ambiente (PNMA) que estabeleceu no âmbito legislativo, a necessidade de inclusão da Educação Ambiental em todos os níveis de ensino, objetivando capacitá-los para a participação ativa na defesa do meio ambiente. Ainda no referido ano, promulgou-se a primeira lei que coloca a Educação Ambiental como um instrumento para ajudar a solucionar problemas ambientais. Na mesma década, a Constituição Federal de 1988 estabeleceu, no inciso IV do artigo 225, a necessidade de: 'promover a Educação Ambiental em todos os níveis de ensino e a conscientização pública para a preservação do meio ambiente'. 
Na década seguinte, em 1991, a Comissão Interministerial para a preparação da Rio 92 considerou a Educação Ambiental com um dos instrumentos da política ambiental brasileira . Em dezembro de 1994, foi criado, pela Presidência da República, o Programa Nacional de Educação Ambiental (PRONEA).

No ano de 2000, a educação ambiental entra na dimensão de programa institucionalmente vinculado ao Ministério do Meio Ambiente, mediante o desenvolvimento do processo de articulação entre os estados visando que além de abordagens generalizadas, a Educação Ambiental também tivesse outro viés de abordagens com base em contextualizações regionais assim como reflexões a respeito de questões de cunho nacional.

Dentro de um pensar mais contemporâneo, nota-se um ímpeto na preocupação governamental acerca das problemáticas ambientais, fato notório a partir do aumento de políticas públicas direcionadas a educação ambiental. Nesta perspectiva, destaca-se a reforma dos Parâmetros Curriculares Nacionais com o objetivo de harmonizar as novas diretrizes em concordância com as exigências e necessidades das atuais normas mundiais, a citar: aperfeiçoamento dos professores; melhoria de laboratórios; revisão de livros didáticos; inserção do contexto local para contemplar as diferentes realidades.

Nas chamadas sociedades contemporâneas do século XXI, a Educação Ambiental tem sido vista como paradigma emergente, pois, mais do que tratar questões/situações descontextualizadas acerca de uma natureza romântica, fantasiosa e idealizada da qual o homem não faz parte, ela tem como foco discutir questões complexas do meio ambiente e, consequentemente, da problemática socioambiental de forma à contribuir para a formação de sujeitos críticos e atuantes.

Ainda no que se refere às mudanças paradigmáticas no contexto da educação ambiental, vale ressaltar o avanço das tecnologias digitais que impulsionaram a criação de grupos de discussão para levantar o debate acerca do tema - possibilitado graças à digitalização e maior disponibilização de importantes textos do Ministério do Meio Ambiente e do Ministério da Educação, por exemplo - sendo capaz de propor novas configurações, inclusive como instrumento para construir ou elaborar projetos, como também exercer o controle social de políticas públicas, com pessoas de vários lugares diferentes do país e de vários segmentos da sociedade, atingindo de maneira incisiva as escolas, seus entornos, governos e sociedade civil.

\section{CONCLUSÕES}

Diante do exposto, é possível afirmar que as sociedades contemporâneas reconhecem que estamos em um período da chamada mudança paradigmática, conforme descrita por Thomas Kuhn, no que se refere às abordagens acerca da problemática ambiental. De maneira paulatina, os estudiosos, os gestores públicos, os empresários e a sociedade civil como um todo, compreendem o meio ambiente como algo do qual todos fazem parte e, assim, necessita de continuadas ações que contextualizem as mais diversas realidades possíveis.

Desta feita, o presente estudo procurou analisar, dentro de uma breve perspectiva histórica, as mudanças paradigmáticas com relação às questões ambientais. Tal contextualização ressalta um avanço 
significativo desta abordagem, principalmente após eventos de caráter mundial que, no Brasil, em específico, resultou em políticas públicas importantes para toda sociedade. No entanto, o processo ainda se encontra em curso, pois, pragmaticamente as ações estão aquém do esperado, ou melhor, daquilo que as sociedades necessitam na atualidade.

Neste pensar, inclui-se a educação ambiental como uma práxis que ainda representa uma importante lacuna a ser melhor planejada e aplicada nos diferentes níveis educacionais, haja vista o fato de grande parte das instituições públicas e privadas de educação ainda não ter um entendimento mais solido acerca das possíveis aplicações das temáticas ambientais em seus currículos, em especial, se essa for de forma contextualizada com os demais campos do saber.

Esta problemática se estende a uma amplitude mais significativa quando ressalta a formação dos profissionais envolvidos, pois, de forma geral, as universidades, em especial as licenciaturas, ainda não formam professores engajados nas questões socioambientais como imprescindíveis para a formação dos alunos enquanto cidadãos críticos e atuantes.

No entanto, as constantes ações de políticas públicas em prol da formulação de leis e projetos, em níveis nacional, estadual e municipal, vislumbrando a adequação, aplicação, monitoramento e fiscalização das práticas referentes à problemática socioambiental e à educação ambiental, são sinalizações positivas. Somado a isto, podemos ressaltar o interesse dos setores produtivos que em suas ações passaram a inserir o 'ambientalmente correto' como marketing positivo e assim, de alguma maneira contribuir para a formação socioambiental.

Neste interim, o homem no contexto ambiental vem ganhando cada vez mais importância nos diferentes contextos sociais. Ainda há muito que fazer, porém, o atual momento nos reporta à ideia de estarmos em curso em um favorável processo de mudança paradigmática em que as concepções socioambientais ganham destaque através de políticas públicas e do interesse social, mediante ações em prol do coletivo.

\section{REFERÊNCIAS}

ASMMANN, H.. Reencantar a educação rumo à sociedade aprendente. Petrópolis: Vozes, 1998.

BRASIL. Conselho Nacional do Meio Ambiente. Brasília: CONAMA, 2002.

BRASIL. Secretaria de Educação Fundamental. Parâmetros Curriculares Nacionais: terceiro e quarto ciclos: apresentação dos temas transversais. Brasília: MECSEF, 1998.

CARVALHO, I. C. M.. Movimentos sociais e políticas de meio ambiente: a educação ambiental aonde fica?. In: SORRENTINO, M.; TRAJBER, R.; BRAGA, T.. São Paulo: Cadernos de Educação Ambiental, 1995.

CAPRA, F. O.. Ponto de Mutação. São Paulo: Cultrix, 1982.
DIAS, G. F.. Educação ambiental: princípios e práticas. 2. ed. São Paulo: Gaia, 2004.

DIAS, G. F.. Atividades interdisciplinares de educação ambiental. São Paulo: Gaia, 1994.

FELIZOLA, M. P. M.. Projetos de educação ambiental nas escolas municipais de Aracaju (SE). Dissertação (Mestrado em Desenvolvimento e Meio Ambiente) - Universidade Federal de Sergipe, São Cristóvão, 2007.

FREIRE, P.. Pedagogia da autonomia: saberes necessários à prática educativa. São Paulo: Paz e Terra, 1997.

GRÜN, M.. Em busca de uma dimensão ética na Educação Ambiental. Campinas: Papirus, 2002.

KUHN, T. S.. A Estrutura das Revoluções Científicas. 2. ed. São Paulo: Perspectiva, 1992. 
PEDRINI, A. G.. Educação ambiental: reflexões e práticas contemporâneas. Petrópolis: Vozes, 1997.

REIGOTA, M. A.. Meio ambiente e representação social. São Paulo: Cortez, 1994.

REIGOTA, M. A.. A floresta e a escola: por uma educação ambiental pós-moderna. São Paulo: Cortez, 1999.

REIGOTA, M. A.. O que é educação ambiental. São Paulo: Brasiliense, 2001.

SANTOS, J. E.; SATO, M.. Universidade e ambientalismo. In: SANTOS, J. E.; SATO, M.. A contribuição da educação ambiental à esperança de Pandora. 3 ed. São Carlos: RiMa, 2006.
SANTOS, B. S.. Conhecimento prudente para uma vida decente. São Paulo: Cortez, 2002.

VALLEJO, L. R.. Políticas públicas e conservação ambiental: territorialidades em conflito nos Parques Estaduais da Ilha Grande, da Serra da Tiririca e do Desengano (RJ). Tese (Doutorado em Geografia) - Universidade Federal Fluminense. Niterói, 2005.

VASCONCELLOS, C. S.. Planejamento: projeto de ensinoaprendizagem e político-pedagógico. São Paulo: Libertad, 2002.

VEIGA, J. E.. A emergência socioambiental. São Paulo: Senac, 2007. 